\title{
Fin de viaje: una novela de aprendizaje feminista o cómo se educa a la mujer para su ingreso a la sociedad
}

Fecha de recepción: 19/5/2020.

Fecha de aceptación: 20/10/2020.

\section{Resumen}

El propósito del presente artículo es efectuar una lectura de Fin de viaje de Virginia Woolf en tanto texto que forma parte de lo que distintos teóricos coinciden en llamar novela de aprendizaje. Considerando asimismo los estudios previos que tuvieron lugar a partir de la obra de Woolf, el trabajo indaga dos cuestiones fundamentales en torno al subgénero en el que se enmarca. En primer lugar, se procura analizar cuáles son las instancias formativas que tiene que atravesar la protagonista para formarse como una ciudadana inglesa que debe ingresar a la sociedad adulta de principios del siglo XX. En segundo lugar y en relación directa con lo anterior, tiene el objetivo de pensar en qué medida puede considerarse como una novela de aprendizaje fallida -puesto que no logra el objetivo final esperado-y, además, feminista.

Palabras clave: Bildungsroman; educación; feminismo; Virginia Woolf.

The Voyage Out: a Feminist Education Novel or How Women are Educated for their Entry into Society

\begin{abstract}
The article intends to shed light upon Virginia Woolf's The Voyage Out from the perspective of what different scholars have conceived of as education novel. Integrating previous criticism on Woolf's narrative, it thus aims to examine the fundamental features of the subgenre in which it roots. First, it inquiries into the diverse formative stages passed through by the character in her formation as an
\end{abstract}


English subject of the beginning of the XXth Century. Second, and immediately related to the concrete ways in which these stages are passed, the article suggests that The Voyage Out could be read as a frustrated specimen of the genre -given that the formative goal is not achieved-and, feminist.

Keywords: Bildungsroman; Education; Feminism; Virginia Woolf.

¡Qué extraño es el vivir! No se sabe nunca hacia dónde se va ni qué es lo que realmente se desea; caminamos con los ojos vendados, sufriendo en secreto, mal preparados siempre, de sorpresa en sorpresa y sin saber nada nunca. Pasamos de unas cosas a otras, y a este proceso que nos ha ido sacando de la nada hasta alcanzar el descanso y la certidumbre últimas es a lo que la gente llama vivir.

(Woolf, 2017: 221)

\section{Introducción}

De acuerdo con Martín Koval (2018), la novela de formación se propone ser un "testimonio literario" del modo en que diversos intelectuales pensaron "la crisis identitaria de la adolescencia y el significado de la adultez o maduración”, es decir, "lo que implica para el sujeto el ingreso a la sociedad por la vía de la internalización-más o menos crítica- de sus normas y valores" (309, cursiva en el original). En consonancia, José Luis de Diego (2007) sostiene que una novela de aprendizaje es aquella en la que se narra el desarrollo de un personaje, generalmente joven, quien atraviesa diferentes experiencias que afectan directamente su posición ante sí mismo, ante el mundo, y ante las cosas, por lo que el protagonista es el principio estructurante de la obra. Aunque, como agrega también este último, "la mayor parte de la bibliografía existente sobre el género coincide en relacionar su origen con el programa ideológico de la Ilustración alemana y el clasicismo de Weimar" (293), a este subgénero pueden asociarse textos de diferentes épocas y procedencias.

Partiendo de esa definición, el propósito del presente artículo es efectuar una lectura de Fin de viaje de Virginia Woolf en tanto novela de aprendizaje. De forma sintética se podría establecer su pertenencia a dicho subgénero en la medida que tiene como protagonista a una joven de veinticuatro años que emprende un viaje fuera de su patria durante el que se pone de manifiesto su falta de aprendizajes sobre la vida para su ingreso a la adultez, para lo cual recibe ayuda de quienes la rodean. Trabajos que persiguen el mismo objetivo son las tesis The Discomfort of Civilization: Destabilizing the Bildungsroman in Virginia Woolf's "The Voyage Out" and "Jacob's Room" (2016), de Maja Lindberg Brekke, y Understanding the subject: Woolf's use of the Bildungsroman in the "Voyage Out" and "Jacob's Room" (2017), de Alexandra Berger.

Ambas teóricas coinciden en señalar que Woolf emplea la novela de formación como subgénero de Fin de viaje, aunque para desestabilizarlo. Lindberg 
Brakke sostiene que en dicha obra el conflicto principal es la lucha entre, por un lado, el deseo de Rachel de autonomía y, por otro, sus mentores, que buscan formarla. Berger, por su parte, demuestra que la problemática fundamental de la narración es la falta de entendimiento de la subjetividad, tanto propia como de los otros sujetos. De esta manera, la primera afirma que Woolf experimenta con el género en tanto que subvierte diferentes cuestiones como el matrimonio y la educación, y que de ello emana, al mismo tiempo, una crítica contundente por parte de la autora hacia las fuerzas sociales patriarcales e imperiales. La segunda, en cambio, considera que el tema principal que es explorado mediante la subversión del género es la dificultad para la comprensión. La teórica explica que una cuestión recurrente en las Bildung femeninas del siglo XIX es que el objetivo final de la protagonista sea el matrimonio, por lo que su aprendizaje va a estar dado por su saber interpretar a las otras personas, lo cual le va a permitir ser una buena pareja. Sin embargo, si bien esta novela sigue muchas convenciones del género en el cual se enmarca (el viaje de la protagonista, la educación que recibe por parte de su tía, su despertar sexual, entre otras), no concluye con la esperada asimilación social de Rachel, dado que esta muere antes de casarse. Esto dejaría ver, de acuerdo con Berger, tanto el modo en que Woolf subvierte el género dando a entender que la comprensión del otro -como meta final del desarrollo femenino- es imposible, al tiempo que problematiza el hecho de que el matrimonio sea el único desenlace en la vida adulta de las mujeres.

Teniendo en cuenta entonces, por un lado, las características de la novela de aprendizaje y los análisis que las teóricas hacen sobre Fin de viaje y su relación con dicho subgénero, y por otro lado los estudios que se han hecho sobre otras características de esta novela y sobre la obra de Woolf en general, este trabajo indaga dos cuestiones fundamentales en torno al subgénero en el que se enmarca. En primer lugar, se procura analizar cuáles son las instancias formativas que tiene que atravesar la protagonista para formarse como una ciudadana inglesa que debe ingresar a la sociedad adulta de principios del siglo XX. En segundo lugar y en vínculo directo con lo anterior, tiene el objetivo de pensar en qué medida puede considerarse como una novela de aprendizaje fallida - puesto que no logra el objetivo final esperado- $y$, además, feminista.

Para lograr estos propósitos, en primera instancia se abordarán algunas cuestiones generales de la obra y de su autora y, a continuación, se procederá a analizar el primero de los puntos anteriormente señalados, es decir, cuáles son los rasgos de la novela que permiten entender a su protagonista como una joven que debe aprender ciertos aspectos de la vida adulta para adentrarse en ella, qué conocimientos tiene que adquirir, de qué manera y quiénes serán sus mentores en dichos aprendizajes. Por último, en relación con su formación, se analizará a la obra como una novela de aprendizaje fallida y feminista, lo que permitirá aportar, al mismo tiempo, una explicación a la muerte de la protagonista. 


\section{Volverse una mujer adulta, ¿qué aprendizajes implica?}

Como afirma María Galbiati (2010), Virginia Woolf (Londres, 1882 - Lewes, 1941) perteneció a la élite intelectual británica y la formación que tuvo es la que pudo recibir en su casa, ya que, como parte de su tiempo, por ser mujer no tuvo derecho a asistir a escuelas ni universidades, ni participar de asuntos políticos o económicos como lo hacían los hombres. A pesar del lugar privilegiado que ocupó en la sociedad como consecuencia de su bienestar económico, lo que le permitió igualmente formarse en muchos aspectos y acceder a una buena posición social, la escritora llevó a cabo una crítica contundente hacia la desigualdad y la injusticia que sufrían todas las mujeres de su época. En Un cuarto propio (1929) y en Tres Guineas (1938) protesta por la exclusión de su sexo de los papeles políticos y sociales, y por la histórica posición sumisa de la mujer frente a la superioridad y los privilegios de los que gozaban los hombres. Estas críticas, que encuentran su lugar más claro en la producción teórica de Woolf, también se observan, en mayor o menor medida, en su producción literaria (8). Tal es el caso de Fin de viaje, ${ }^{1}$ la primera novela de la autora. Su escritura comenzó en el año 1908, bajo el nombre de Melymbrosia, pero tras una serie de revisiones y modificaciones, salió publicada el 26 de marzo de 1915 tal como se la conoce hoy en día. En esta obra, siguiendo también a Galbiati, se verifica el posicionamiento crítico de la autora sobre los individuos, la sociedad, y los asuntos más importantes de su tiempo: los roles sociales de los hombres y las mujeres, el colonialismo y el imperialismo británico (10).

La narración comienza centrándose en la pareja de Ridley y Helen Ambrose, quienes caminan por las calles de Londres rumbo a un buque en el que se encontrarán con su sobrina, Rachel Vinrace. Los tres, acompañados por otros pocos personajes, se embarcan rumbo a la ficcional antigua colonia Santa Marina, en América del Sur. Aunque al principio Rachel aparece muy poco en la narración, y de hecho es bastante ignorada por el resto, poco a poco la trama se va centrando en ella y su viaje. La joven tiene veinticuatro años y viaja durante un tiempo prolongado con los tíos antes mencionados, un amigo de la familia Vinrace, su propio padre -que es también el dueño del barco-, y Richard y Clarissa Dalloway. Tanto dentro del barco como fuera de este, cuando finalmente llegan a destino, Rachel se cruza con distintos personajes que hacen que este viaje no se trate únicamente de algo exterior, sino también interior. Es decir, este viaje, tal como afirma Lindberg Brekke (2016), no sólo implicará para ella una salida desde el encierro de su hogar hacia el exterior, representado por un continente para ella desconocido, sino que también significará para la joven un viaje hacia su interior, un descubrimiento de ella misma. En su conjunto, entonces, tanto el viaje objetivo como el viaje subjetivo que experimenta la protagonista -una joven cuidadosamente educada y sobreprotegida por su familia y fundamentalmente por su padre-, logran que comience su ingreso como mujer adulta a la sociedad inglesa de su época.

1 De aquí en adelante, para las citas de esta obra colocaremos solamente el número de página entre paréntesis, que corresponde a la edición indicada en la bibliografía. 
Distintas descripciones de Rachel hacen ver que se trata de una joven cuyos únicos pasatiempos son tocar el piano y leer, que carece de conocimientos (o de conocimientos considerados válidos para quienes la rodean) y que, por lo tanto, necesita de mentores que la eduquen y le enseñen todo lo que desconoce. "Había sido educada como la mayoría de las muchachas ricas de su generación”, sostiene el narrador. Y seguido a esto agrega que "ningún tema le era conocido a fondo" ya que esta enseñanza, como desarrolla luego, "no enseñaba nada" acerca del mundo (Woolf, 2017: 21). Bajo esta idea, varios son los personajes que se ponen en el rol de guías y le ofrecen de manera implícita la formación que requiere. Como explica Koval (2018), el joven protagonista de una novela de formación está atravesando la adolescencia. Y esta etapa, afirma, es narrada como "un estadio intermedio" caracterizado por la separación respecto de la sociedad, la irresponsabilidad, la inmadurez, la soledad anímica y la vulnerabilidad, entre otros aspectos, por lo que el individuo necesita "de la guía de otros, de adultos ya maduros y capaces de comprender sus disposiciones internas, pues aquel no puede valerse sólo ni ‘descubrirlas' por sí mismo” (310).

Uno de los principales personajes que va a querer ocupar este lugar de guía es su tía Helen, quien primero no se siente cómoda estando en la embarcación y manifiesta que su sobrina no es de su agrado, pero conforme pasa el tiempo va a sentir deseos de enseñarle diversas cosas. De esta manera, el narrador sostiene:

Helen se interesaba por su sobrina, le gustaría guiarla y aconsejarla, enseñarle a vivir, a ser razonable. La muchacha había formado un concepto erróneo del político y su acción, opinión de la que sólo podría sacarla una persona que tuviese ascendiente sobre ella (61).

Estas enseñanzas que pretende brindarle su tía están fundadas en el propósito de que Rachel aprenda a vivir de manera más autónoma, como otro de los aprendizajes que debe adquirir la joven. Así, cuando su tía manifiesta su deseo de que ella se entienda a sí misma y viva por sí misma, mantienen la siguiente conversación:

- ¿Puedo ser yo mi... mi... misma -tartamudeó-, a pesar de ti, a pesar de los Dalloway, del señor Pepper, de mi padre, de mis tíos... y de todos?-preguntó [...].

-No sólo puedes serlo, sino que ya lo eres. Hasta ahora has guardado oculta tu verdadera personalidad -contestó Helen seriamente (62).

Rachel Vinrace fue criada por las dos hermanas de su padre, ya que su madre murió cuando ella tenía sólo once años: "Durante la niñez y la adolescencia, creció entre mimos y preocupaciones por su salud”. Y ya una vez pasada la adolescencia, sostiene el narrador, "estos mimos se dirigieron por otros derroteros de índole moral" por lo que "hasta hace poco había ignorado la mayoría de las cosas referentes a la vida íntima” ya que tanto sus tías como su propio padre ejercían una "censura" sobre esto (22). En consecuencia, su "vida íntima" es un terreno para ella desconocido que, en el viaje que emprende, también comenzará a descubrir. 
Fin de viaje: una novela de aprendizaje...

Vivir de manera más autónoma, tomar conocimiento de su intimidad y conocer de política o, de manera más amplia, adquirir conocimientos sobre la sociedad en la que está inmersa, van a ser tres aprendizajes que Rachel debe adquirir para comenzar a formar parte de la vida adulta. La autonomía es algo que poco a poco Rachel comienza a vivenciar, habiendo dado el primer paso en el comienzo del viaje y acrecentándola cuando decide quedarse en Sudamérica con sus tíos, lejos de su padre. Allí, cuando conoce a un joven del que se enamora y con quien comienza un romance, descubre también su intimidad. Y en relación con el tercer punto, es decir, en cuanto a su conocimiento sobre la sociedad, se podría afirmar que su principal mentora es la pareja Dalloway. Ellos, a través de diferentes formas, le van a enseñar de manera más o menos directa cómo es la sociedad inglesa que debería integrar.

Clarissa Dalloway y su marido, Richard Dalloway, son dos pasajeros del barco que no eran esperados ni tenían permitido el acceso. Sin embargo, enuncia el narrador:

\begin{abstract}
Este señor había sido elegido una vez miembro del Parlamento, y en cuanto a su esposa, era hija de un Par y por tales motivos creían tener derecho exclusivo a cuanto pedían o solicitaban. [...] pasaron todas las objeciones, no le hicieron el menor caso, y le mostraron una carta de Lord Glenaway en la que le rogaba, como un favor personal, que los admitiera a bordo (25).
\end{abstract}

Posiblemente esa sea la primera enseñanza que Clarissa, protagonista de la futura novela La señora Dalloway (publicada por Woolf en 1925) y su marido, le ofrecen a Rachel sobre las relaciones sociales: el valor de la posición social para lograr lo que uno quiere. Sin embargo, su mayor enseñanza va a ser sobre cuál es el lugar que tiene asignado la mujer de su época, qué posición ocupa frente al sexo opuesto, cuál es el rol de cada uno en la política y, en definitiva, qué significa ser un hombre y qué significa ser una mujer en una sociedad patriarcal.

Si todos los personajes de la novela son considerados como "símbolos", tal como afirma Rachel de quienes la rodean (y de este modo piensa en sus tías, su padre y el resto como representantes del "símbolo de la edad, de la juventud, de la enfermedad"), se podría llegar a concluir que el matrimonio Dalloway representa el símbolo del orgullo inglés. Ambos sienten una profunda admiración hacia el Imperio Británico y todas las características que lo conforman, expresando puntos de vista sumamente conservadores y machistas sobre la política, la sociedad y los sujetos. Así, por ejemplo, en una conversación que mantiene con Richard, Clarissa sostiene:

-No puedo dejar de pensar en Inglaterra, Dick [...]. Esta soledad aviva el recuerdo y sobre el mar pienso en lo mucho que significa ser inglés. En nuestra marina, en la gente de India y África, en nuestra marcha ascendente siglo tras siglo, gracias a hombres como tú, Dick. Me siento orgullosa de ser inglesa, no concibo que pudiera ser de otra nacionalidad. [...]

Una visión de la historia patria cruzaba por su mente. Los reyes y los ministros se sucedían y por encima de todos, la Ley. Se dejaba llevar por la ruta de la política conservadora, que iba desde Lord Salisbury a Alfred, encerrando entre sus mallas los mejores florones de los cinco continentes (35). 
Entre ellos, además, los roles sobre cuáles son los lugares de las mujeres y de los hombres están claramente establecidos. Clarissa es la representación de la mujer que acata todas las normas de la sociedad patriarcal. Es una "gran señora" (33), bella, encantadora, femenina y refinada, que prefiere morir de hambre antes que sentarse en la mesa con el mismo vestido que llevó toda la tarde(Id.). Es, además, una mujer que tiene prohibida por su marido la participación en política. En relación con Rachel, ella siente deseos de "avivarla antes de que sea demasiado tarde” (Id.), razón por la cual se acerca cada vez más a la joven, quien siente una profunda atracción por ella, y durante su viaje asume casi el rol de una madre.

En la primera conversación que mantienen en privado Rachel le dice a Clarissa que ella nunca se casará, y la segunda pone en duda lo dicho: "Yo no lo diría con tanta seguridad" (42), sostiene. Y cuando Rachel por primera vez siente deseos de contarle cosas que nunca le había contado a nadie, y le confiesa sentirse sola, la señora Dalloway refuerza la idea de que para la felicidad de la mujer es necesario que cuente con un hombre: "A tu edad me sucedía lo mismo. Nadie sabía entenderme... hasta que encontré a Richard. Él me dio cuanto deseaba” (43).

La inferioridad de la mujer en relación al hombre, y en particular la sensación de inferioridad que siente Clarissa respecto de su marido, se vuelve nítida para el lector en diversos acontecimientos narrados. Sobre ello, el siguiente fragmento de las divagaciones de la señora Dalloway en las que compara a su pareja con la figura de Cristo, es elocuente:

- ¿Es conveniente para una mujer como yo vivir siempre con un hombre moralmente superior? Estamos siempre pendientes de él. Lo que yo siento por Dick es algo así como lo que mi madre y demás antepasados femeninos debieron sentir por Cristo. Sí, debe ser un sentimiento muy semejante (36).

Richard Dalloway, por otro lado, es "un verdadero gentleman inglés" (52) y a su modo le enseña a Rachel, también, cuál es el lugar de la mujer en relación con el hombre tanto en las relaciones como en la vida pública. En la única conversación que mantienen a solas ambos discuten sobre el rol de la mujer en la política y Richard sostiene:

-No hay ninguna mujer con espíritu político. Tienen todas las virtudes, soy el primero en reconocerlo; pero no hay ninguna mujer que sepa apreciar el verdadero significado de la palabra "estadista", y si he de serle franco, espero y confío no encontrar nunca a esa mujer (48).

Rachel siente, ante estas afirmaciones, "vanidad, despecho y un imperioso deseo de hacerse comprender por el señor Dalloway” (48). Sin embargo, lejos de llegar a un acuerdo, cuando la joven se va, él la sigue hasta su habitación, y allí, luego de reparar en su belleza, la besa "primero suavemente y luego con tal pasión que llegó a hacerle daño con los huesos del rostro" (55), seguido de un intento por justificar su accionar diciéndole que fue ella quien lo tentó. 
Fin de viaje: una novela de aprendizaje...

La protagonista reacciona tanto de manera negativa como positiva ante esto. Si bien dice que le gustó, en la voz narradora son mucho más notables las consecuencias negativas que este hecho acarrea para ella. Esa misma noche adopta una actitud extraña, está pálida y “su sueño fue una espantosa pesadilla” (56) que la angustia y le hace sentir temor por lo que pudiera venir del exterior de su habitación:

\begin{abstract}
Se veía encerrada en un oscuro túnel cuyas paredes iban acercándose lentamente, amenazando aplastarla e impidiéndole respirar. Cada vez que intentaba huir se le aparecía un enanillo, de largas y negras uñas que mordía incesantemente, impidiéndole pasar y sacando la lengua burlonamente. Sentíase oprimida por esta angustia, cuando despertó sobresaltada. [...] La idea de que la perseguían seguía atormentándola, a pesar de estar despierta. Cerró la puerta con llave (56.).
\end{abstract}

Cuando Helen advierte el "trastorno psíquico" (59) de su sobrina, cree conveniente ayudarla. Y lo hace diciéndole, por un lado, que lo que ocurrió es completamente esperable porque los hombres son así: "no temas", le dice, "es lógico que los hombres intenten besarte o casarse contigo. Eres bonita" (Id.). De esta manera se observa, entonces, que en la formación de Rachel acontecen nuevos hechos. Por un lado, inicia su encuentro con el otro sexo -a partir de un beso que ella no pidió y cuyas consecuencias negativas son claras-y, por otro lado, vivencia en su cuerpo la estructura patriarcal de las relaciones entre los hombres y las mujeres de la cual, al menos en el plano íntimo, aún era ajena. Pero también va a obtener dos enseñanzas más de parte de su tía respecto de lo ocurrido. Primero, que eso es lo corriente, y que sería "triste" intentar "sacar las cosas de su cauce normal" (Id.). Y segundo, que tanto besar como querer casarse con alguien son privilegios masculinos. Finalmente, Rachel va a obtener un aprendizaje más, esta vez por cuenta propia, y es que debe tener cuidado: “Por eso no puedo pasear sola!” (60) exclama.

La protagonista, a quien todos ven como una joven ingenua a la que le faltan sabiduría y experiencia, y se ve a sí misma "como un ser guardado entre altísimas paredes, perpetuamente vigilada y a oscuras, con una vida monótona, sombría" (Id.), se queda algunos meses viviendo con sus tíos en Sudamérica, lejos de su padre y de su patria. Su tía, Helen, queda bajo su responsabilidad con el fin de procurar que socialice más con la gente a fin de educarla y hacer de ella "una verdadera mujer" (63), tal como su padre le encargó.

En la isla sudamericana Rachel percibe muchos cambios en su vida. Ya lejos de su padre, pasa las tardes conociendo el mundo y aprendiendo lo que su tía puede enseñarle. Helen la lleva a "ver la vida" (71) en sus paseos y al poco tiempo, afirma el narrador, "se notaban en ella una mayor seguridad y aplomo en su forma de conducirse". Además, "se atrevía a tomar parte en las conversaciones" (70). A los tres meses su tía comprendió que "un cambio se operaba en Rachel” (Id.):

Se había desquitado sobradamente de la monotonía de su vida anterior, a pesar de que aparentemente Helen no ejercía sobre ella ninguna influencia. Rachel estaba menos retraída y seria (88). 
Helen instaba a que su sobrina se acostumbrara a conversar con ella, "deseaba que Rachel hablara por sí sola, sin coacciones y no dependiera de nadie" (Id.). Le ofrecía música y libros, y de entre estos últimos eligió los modernos que antes le estaban vedados, y a partir de estos conoció por primera vez "los problemas de importancia de la vida" (Id.) y aprendía cada vez más:

Cosasy palabras para ella desconocidas se infiltraban en su mentey las manejaba con la inseguridad de las cosas nuevas. Formaba conclusiones que variaban continuamente, según la marcha de la vida cotidiana (89).

Rachel comienza a frecuentar lugares antes desconocidos tanto en el nuevo continente como en su propia subjetividad. Conoce a mucha gente que se hospedaba en un hotel cercano, y entre todos ellos a dos amigos, Terence Hewet y John Hirst, con quienes entabla diferentes conversaciones que la hacen reflexionar sobre temas ya anteriormente nombrados, como el lugar de la mujer en la sociedad, pero también sobre literatura, música, religión.

La protagonista se enamora de Terence Hewet y comienzan una relación. Este personaje también ocupa el rol de "educador" de Rachel y ella a su lado aprende muchas otras cosas hasta ese entonces ignoradas. En estos nuevos aprendizajes es posible observar, como en los anteriores, una crítica contundente por parte de Woolf hacia la cultura del patriarcado. Así, tres temas que recorren toda la obra y que para Rachel no resultan ajenos son el matrimonio, el sufragio femenino y la diferencia entre los sexos.

En relación con el matrimonio, se observa que Rachel siente sobre sus hombros la presión de su familia (además de la de Clarissa, como anteriormente se analizó) para que, sin perder su "feminidad", se case con un hombre.

- Hace poco tuve noticias de la tía Bessie -replicó Helen-. Teme que se te estropeen las manos si estudias tanto.

- ¿O acaso que me ponga musculosa y eso me impida casarme?

-No es eso precisamente -corrigió Helen.

-Claro, ella no lo diría así, pero es lo que piensa -dijo Rachel, soltando un suspiro (10).

Sus primeras reacciones sobre este tema, como se observa, son negativas. Ella niega rotundamente, en principio, la idea de casarse, y luego interpela a sus distintos mentores sobre la necesidad del matrimonio. “Por qué se casan las personas?” (42), le pregunta a Clarissa primero, y más tarde cuestiona a su pareja consultándole: “¿Tenemos que casarnos?” (200).

El sufragio femenino es también un tema recurrente en la novela. El voto femenino en la Inglaterra de Virginia Woolf comenzó a tener mayor lugar de discusión hacia principios del siglo XX, y particularmente a partir de 1903, cuando la activista Emmeline Pankhurst fundó el Sindicato Político y Social de las Mujeres, y recién en 1918 las mujeres mayores de 30 años lograron el derecho al sufragio. En 
medio de este contexto, la escritora elige que este sea otro de los temas que tanto los personajes que rodean a Rachel como ella misma discutan. En la obra resulta notable que los personajes que opinan sobre este tema sean, en su mayoría, los hombres, quienes remarcan que la política no es un lugar para las mujeres o que, votando o no, estas poco podrían cambiar la realidad. Así, el padre de Rachel es el primero en manifestar su posición: "iPreferiría verme enterrado antes de que una mujer tuviese derecho a votar en Inglaterra!" (28), y el novio de Rachel le dice en una charla que siente mucho "que con voto o sin él las mujeres consigan nada" (148).

A partir de todo lo analizado anteriormente puede observarse que la diferencia entre los sexos es un tema que recorre toda la narración. Sin embargo, no sólo es notable en las cuestiones hasta ahora señaladas, sino que de manera mucho más explícita, varios personajes de la obra defienden la idea de que hombres y mujeres son muy disímiles entre sí. A modo de ejemplo, uno de los personajes masculinos le dice a una mujer: "Me inspira tal confianza que puedo hablarle como lo haría con un hombre. Las relaciones entre distintos sexos..." (113). Así también, Terence le dice a Rachel: "iLos hombres y las mujeres son tan distintos! Tú no puedes comprenderlo, es posible que no te des cuenta” (214).

La diferencia entre los sexos sobre la cual varios personajes dialogan también muestra las relaciones desiguales que entre ellos se establecen. Son varios los personajes - tanto femeninos como masculinos-que alegan sobre la superioridad del hombre sobre la mujer. Además de los ejemplos ya expuestos de la relación de Clarissa con su marido, Terence - por nombrar otro caso-lee una novela en la que el protagonista se refiere a la mujer como "la enemiga y el parásito del hombre" (210). Asimismo, Pepper -otro de los hombres que viaja en el barco- dice no encontrar una mujer "que le inspire respeto" (14). Hirst, que es presentado como el "ejemplo del hombre" (209), es intelectual y arrogante, y le deja ver a Rachel lo superior que es frente a ella.

Terence, por otro lado, es el único personaje masculino que se propone discutir este vínculo desigual. Así, desmiente que los hombres deban dominar a las mujeres diciéndole a su novia Rachel:

El respeto que las mujeres, incluso las mujeres cultas, sienten hacia el hombre [...], creo que obedece a una especie de dominio que nosotros poseemos sobre ellas semejante al que decimos poseer sobre los caballos. Se imaginan que somos tres veces más importantes de lo que somos realmente (148).

En la misma conversación, él también le pregunta detalles sobre su vida en Londres con sus tías, y efectúa una crítica sobre la situación de la mujer en su época:

Estamos a comienzos del siglo $X X$ y hasta hace pocos años ninguna mujer se atrevía a salir sola y así ha sido durante miles de años. Una vida silenciosa, retraída, sin representación social. Hay mucho escrito sobre las mujeres, burlándose o adorándolas... pero rara vez estos escritos emanan de ellas. Creo 
que los hombres no las conocemos en lo más mínimo. Ignoramos cómo viven, qué sienten y cuáles son sus ocupaciones. La única confidencia que de ellas conseguimos los hombres son amores. Pero de las vidas íntimas de las solteras, de la mujer que trabaja o educa y cuida a la infancia, como por ejemplo sus tías, la señora Thornbury... la señorita Allan, de ésas no conocemos absolutamente nada. [...] Piense en un tren compuesto de quince vagones con varios compartimientos reservados especialmente para los fumadores. ¿No le exalta a usted esa prioridad del hombre? ¿No se ríen de nuestra supuesta superioridad y petulancia? ¡Todo es una farsa! (152)

Este cuestionamiento que Terence lleva a cabo acerca de los hombres de su tiempo y, en general, acerca de la sociedad patriarcal en la que están insertos, deja entrever una crítica que, años más tarde, Woolf desarrolla en Un cuarto propio. En este largo ensayo, publicado en 1929 , la escritora lleva a cabo un análisis socio-político desde una perspectiva de género. Y entre los diversos factores que analiza, pone en cuestión justamente el fuerte contraste existente entre la cantidad de hombres que escriben y opinan sobre las mujeres, frente a la poca participación que tienen las mujeres en la sociedad, incluso para opinar, de cualquiera sea el tema.

Como consecuencia de la marcada diferencia que los personajes perciben entre los hombres y las mujeres -y que efectivamente existe en el plano legal, político, social, económico-, se manifiesta la falta de entendimiento entre los sexos. Esta idea de la diferencia entre los sexos también es desarrollada por la escritora en otro de sus textos críticos posteriores, Tres guineas. Esta extensa carta comienza con una interpelación de Woolf a su interlocutor varón, diciéndole que ellos dos, por sus géneros, están separados por un "un abismo" (9) que genera una gran “dificultad de comunicación” (8). Además de Alejandra Berger-cuyo trabajo ya fue mencionado en la introducción a este artículo-, Maria Galbiati y Peter Harris, en su artículo "Reality and language in The Voyage Out, by Virginia Woolf” (2010), muestran que en esta novela se observan diferentes formas de incomprensión, tanto directas como indirectas, y que todas tienen como causa la incapacidad de expresar la experiencia humana por medio del lenguaje. Son varias las ocasiones en las que los personajes no logran comunicarse bien entre sí.

De hecho, la novela comienza con la pareja Ambrose caminando por Londres, rumbo a la embarcación, y mientras Helen llora, su marido no comprende el motivo de sus lágrimas ni busca comprenderlas. Esto se da, explican los teóricos, porque Woolf está interesada en mostrar esta imposible comprensión del otro, incluso en una de las relaciones más íntimas como es el matrimonio. A pesar de la complicidad y el conocimiento mutuo, ambos son conscientes de que el entendimiento total no existe y ello tiene lugar en reiteradas oportunidades. Sin embargo, cabe aclarar que, tal como mencionan los autores, no es únicamente entre sexos opuestos, sino que los personajes entienden que la incapacidad para transmitir la experiencia por medio del lenguaje se da en un plano más general. En Rachel dicha dificultad es clara y como consecuencia de ello se refugia en la música: "La música puede expresar todos sus sentimientos mejor que la literatura. En ésta hay mucho... - calló como si no encontrara la palabra deseada_-"(148). 
Otros personajes se replantean el hecho de escribir literatura. Se preguntan si sirve escribir cuando los otros no entienden. Terence intenta escribir una novela "sobre los sentimientos íntimos que no se expresan, sobre lo que la gente siente y no dice" (154), sin embargo, siente que "las dificultades son inmensas" (Id.) porque a nadie le importaría. Él en reiteradas ocasiones presenta sus dificultades para entender a Rachel y para comprender lo real. "Me parece que lo que yo quiero hacer al escribir novelas es algo parecido a lo que hace usted al tocar el piano, ¿no es así? Ambos intentamos descubrir lo que se oculta bajo las apariencias" (156) le pregunta a la protagonista. Y como la única forma de conocer lo que le ocurre, qué piensa, qué le sucede, es por medio del lenguaje -un lenguaje puesto en crisis-, Terence tiene la sensación de que no logra conocerla y unirse a ella como quisiera. Así, luego de una charla que ambos mantienen, el narrador sostiene:

\begin{abstract}
Al pensar en cuanto se habían dicho le pareció que todo fueron divagaciones inútiles, que si les habían acercado en algunos momentos, en la mayoría les mantuvieron profundamente separados. Por eso ahora se sentía insatisfecho, sin saber a ciencia cierta cuáles eran los sentimientos de Rachel. ¿Para qué servía hablar? «Para eso» tan solo: para hablar. (157)
\end{abstract}

En definitiva, tanto durante su permanencia en el barco como durante su estadía en el continente sudamericano, en Rachel se opera una serie de cambios y finalmente decide concretar el matrimonio con Terence y volver a Inglaterra. Sin embargo, cuando todos estos planes ya están por volverse realidad, la protagonista enferma y, hacia el final de la obra, muere.

De esta manera, entonces, la protagonista, que había comprendido las características de su época tanto como su propia subjetividad, y había percibido en ella su transformación, no concluye de manera positiva su etapa de educación, y muere antes de que finalmente pueda lograr el propósito de la novela: su integración a la sociedad. Esa es la primera hipótesis que pretende demostrar el presente trabajo. Si bien, por diferentes vías y a través de la guía de distintos personajes, Rachel aprende cada vez más cuáles los valores y las normas de la sociedad a la que debe insertarse como adulta, no logra hacerlo y su "formación” no se ve consumada.

Como afirma Koval, que el héroe devenga adulto significa que abandone la "indeterminación adolescente", y que "deba deponer sus ideales artísticos" (317). Como contraparte, su agregación a la vida adulta establece como valores positivos la maduración, la paternidad, el matrimonio y la estabilidad social (Id.). Rachel, por su parte, tenía el imperativo familiar de integrarse a una sociedad fuertemente marcada por el colonialismo y las relaciones desiguales de género (Lindberg, 2016). Su padre aspiraba a conseguir un lugar en el Parlamento y procuraba que para ese entonces Rachel “estuviera bien situada” (63) para que participe en sus comidas, en sus fiestas nocturnas y atendiera y se relacionara con personas del ámbito político. Tenía, para ello, que convertirse en "una verdadera mujer" (Id.). La socialización con los otros, en este sentido, es el eje principal en la educación de Rachel. Devenir una mujer adulta significa para ella vincularse con diferentes personas, muchas de las cuales, como se observó, ocupan el lugar de guías o maestros. 
Fin de viaje: una novela de aprendizaje...

Salir del umbral entre la juventud y la adultez y ser, por fin, una ciudadana en la sociedad británica de comienzos del siglo XX la obliga a internalizar diferentes pautas sociales, políticas, económicas y culturales, todas ellas empapadas de la relación desigual entre los géneros. Rachel debía aceptar ser una mujer sumisa, en inferioridad de condiciones respecto de los hombres, valorar a su padre y a todos los "hombres ejemplares", y lograr el objetivo para el que fue cuidadosamente educada, es decir, casarse y tener hijos.

Sin embargo, Rachel es cada vez más consciente de su transformación, de su crecimiento, y sus críticas a su antigua educación son cada vez más contundentes. Además de tratarse de una novela de aprendizaje fallida cuyo propósito final no se logra, la segunda hipótesis de este análisis es que se trata de una novela de aprendizaje en la que subyacen ideas feministas. Rachel aprende las características y las reglas de la vida en la cual debe insertarse, pero no las internaliza, sino que, por el contrario, las discute, cuestiona o problematiza. Ello es notable, por ejemplo, en la siguiente conversación con Vinrace, cuando él cuestiona -nuevamente-los privilegios de los hombres y, en particular, los privilegios de quien se muestra como el modelo de hombre en la obra, el joven intelectual Hirst:

\footnotetext{
-[Hirst] Encuentra muy natural que la hermana se vaya a dar la comida a los conejitos para que él disfrute de la sala de estudios sin interrupciones molestas. [...]

-Pero... ¿y su hermana?

-A ella nadie la toma en serio, pobrecita... Ella a dar de comer a los conejitos.

-Yo he dado de comer a los conejitos durante veinticuatro años; ahora me parece imposible (149).
}

Durante la misma conversación, cuando Vinrace hace su crítica a la supuesta superioridad de los hombres en la vida diaria, ella también se cuestiona su pasado, y su juicio esta vez cae exclusivamente encima de su padre:

[Rachel] repasó mentalmente sus 24 años. Intentó describir más cuidadosamente a sus tías. Éstas tenían cierto respeto hacia su padre, que ejercía en la casa una autoridad. [...] Él las trataba siempre en broma pero con cierto desdén. Para Rachel todo lo que hacía su padre era perfecto. [...] Pero las palabras de Hewet conmovían el edificio de sus pensamientos. Ella se había sometido siempre a la voluntad de su padre, quizás por influencia del comportamiento de sus tías, y tal influencia es la que regía su vida. [...] Sintió deseo de romper todo aquello en añicos (152).

El matrimonio, esperado por su familia como un acontecimiento clave en su vida, es puesto en tela de juicio también, como se observó con anterioridad. Asimismo, la idea de tener hijos es replanteada por Rachel ya que dice que no desea tenerlos.

La protagonista únicamente acepta, dentro de estos imperativos sociales, la idea de casarse ya que junto a Vinrace ella comprende que puede seguir siendo libre y que puede seguir manteniendo su independencia, que "a pesar de casarse con él [...], de gozar y padecer con él íntimamente, sería independiente de él" (221). Sin embargo, el trágico desenlace no se lo permite demostrando 
la rigidez de las normas sociales. Estas pautas tienen tal rigidez que Rachel, intentando salirse de lo establecido, no tiene otro destino que morir para-sólo así- poder ser libre. La tercera y última hipótesis -que, a su vez, resulta de las anteriores-, entonces, es que la muerte de Rachel puede ser pensada como una crítica por parte de Woolf hacia la rigidez de las normas sociales. Rachel, que intenta vivir una vida alternativa a las normas que su familia desea que internalice, no tiene otro destino que morir como consecuencia de la coerción que ejercen tales reglas.

\section{Conclusiones}

A modo de conclusión se podría afirmar que la novela Fin de viaje explora diversas cuestiones entrelazadas cuyo análisis tuvo por objeto el presente artículo.

Por un lado, la narración es una indagación de la interioridad de Rachel, sus reflexiones, sus sueños, alucinaciones y temores, al tiempo que es una crítica a la naturaleza destructiva de las fuerzas sociales de la sociedad inglesa, patriarcal e imperial, de comienzos del siglo XX. En la medida que la formación de su protagonista es el núcleo central de la obra, se procuró observar cuáles son las cuestiones que la vinculan al subgénero novela de aprendizaje, y se llegó a la primera hipótesis de que la obra es una novela fallida en tanto que la integración final de la joven a la sociedad adulta es un objetivo que no logra consumarse.

Por otro lado, y en relación con esto último señalado, la obra es una historia que sigue los parámetros convencionales del género y, paralelamente, una historia que los subvierte. Diversos teóricos (Lagos, 1996; Vadillo Buenfil, 2012; entre otros) discuten si las novelas de formación con protagonista femenina son en realidad una desviación del modelo original con personaje principal masculino o si deben analizarse del mismo modo independientemente de ello, si la formación en uno u otro caso implica lo mismo, entre otras cuestiones. En este trabajo se analiza la obra teniendo en cuenta las características del género novela de aprendizaje, independientemente del sexo del personaje principal, pero prestando especial atención a las correspondientes cuestiones a las que se enfrenta la protagonista por su condición femenina. Fin de viaje se trata de la representación literaria de la crisis identitaria y de la incorporación a la sociedad de una mujer en un momento histórico determinado: la Inglaterra de comienzos del siglo XX. Partiendo de esta idea es que se postula, como segunda hipótesis, que esta obra es una novela de aprendizaje femenina feminista, en tanto que se problematiza la asimilación de las normas patriarcales de la sociedad. Rachel se niega a hacer suyas estas formas de vida y, frente a la fuerza de las leyes sociales, como tercera hipótesis, Woolf no encuentra para ella otro destino que la muerte.

Para finalizar se podría establecer que las novelas de aprendizaje con protagonista mujer resultan un buen caso para observar de qué manera opera la diferencia 
sexual en la representación literaria de la experiencia femenina, ya que este tipo de textos pone el foco en su proceso de crecimiento y educación. De esta manera es posible, entonces, indagar por medio de la literatura cómo se construye y cuál es el origen de las diferencias sexuales, y cuáles son las nociones acerca de lo que significa ser mujer en determinada cultura y en determinado momento histórico. 


\section{Q Bibliografía}

"Berger, A. (2017). Understanding the subject: Woolf's use the Bildungsroman in The Voyage out and Jacob's room. Tesis doctoral. Columbia: Faculty of the Graduate School, University of Missouri.

"De Diego, J. (2007). Literatura y educación: la novela de aprendizaje. En Arrabal, núm. 5, pp. 293-298.

" Galbiati, M. (2010). Consciência literária e posicionamento político no processo de composição de The Voyage Out, de Virginia Woolf. En Revista Escrita, vol. 11, pp. 1-14.

" Galbiati, M.; Harris, P. (2010). Reality and language in The Voyage Out, by Virginia Woolf. En Acta Scientiarum Language and Culture, vol. 32, núm. 1, pp. 67-72.

"Koval, M. (2018). Vocación y renuncia. La novela de formación alemana entre la Ilustración y la Primera Guerra Mundial. Buenos Aires: Editorial de la Facultad de Filosofía y Letras Universidad de Buenos Aires.

"Lagos, M. (1996). En tono mayor. Relatos de formación de protagonista femenina en Hispanoamérica. Santiago: Editorial Cuarto Propio.

" Lindberg Brekke, M. (2016). The Discomfort of Civilization: Destabilizing the Bildungsroman in Virginia Woolf's The Voyage Out and Jacob's Room. Tesis doctoral. Bergen: Department of Foreign Languages, Universitas Bergensis.

"Vadillo Buenfil, C. (2012). El Bildungsroman en las narradoras españolas de posguerra: 1940-1960. Tesis doctoral. Madrid: Facultad de Filosofía y Letras, Universidad Autónoma de Madrid.

"Woolf, V. (2017 [1915]). Fin de viaje. En Freeditorial. <https://freeditorial.com/es/ books/fin-de-viaje> (consulta: 5/5/2020].

"Woolf, V. (2008 [1929]). Una habitación propia. Trad. de L. Pujol. Barcelona: Seix Barral.

"Woolf, V. (1999 [1938]). Tres guineas. Trad. de A. Bosch. Barcelona: Lumen. 